\title{
Assessment of Knowledge, Attitude and Practice Towards Emergency Contraceptive Methods Among Female Students in Seto Semero High School, Jimma Town, South West Ethiopia
}

\author{
Asmare Tesfa ${ }^{1}$, Asmamaw Demis Bizuneh ${ }^{1}$, Temamen Tesfaye ${ }^{1}$, Addis Adera Gebru ${ }^{2, *}$, \\ Yonas Yimam Ayene ${ }^{2}$, Birhan Alemnew Tamene ${ }^{2}$ \\ ${ }^{1}$ Department of Nursing and Midwifery, College of Public Health and Medical Science, Jimma University, Jimma, Ethiopia \\ ${ }^{2}$ Department of Nursing, Faculty of health Sciences, Woldia University, North Wollo, Ethiopia
}

\section{Email address:}

asmamawdemis@gmail.com (D. B. Asmamaw), addisaderagebru@gmail.com (A. G. Addis), Yonasyimam@gmail.com (Y. A. Yonnas), birhanalemnew12@gmail.com (A. T. Birhan)

\section{To cite this article:}

Asmare Tesfa, Asmamaw Demis Bizuneh, Temamen Tesfaye, Addis Adera Gebru, Yonas Yimam Ayene, Birhan Alemnew Tamene. Assessment of Knowledge, Attitude and Practice Towards Emergency Contraceptive Methods Among Female Students in Seto Semero High School, Jimma Town, South West Ethiopia. Science Journal of Public Health. Vol. 3, No. 4, 2015, pp. 478-486.

doi: $10.11648 /$ j.sjph.20150304.15

\begin{abstract}
Background Despite the availability of highly effective methods of contraception, many pregnancies are unplanned and unwanted. These pregnancies carry a higher risk of morbidity and mortality, often due to unsafe abortion. Many of these unplanned pregnancies can be avoided using emergency contraception. Literature reveals that there is existence of knowledge, attitude and practice gaps on emergency contraception in the world including Ethiopia. Thus this study aimed to fill these gaps. Objective: To assess knowledge, attitude and practice towards emergency contraceptive methods among female students in Seto-Semero high school Jimma town, south west Ethiopia. Methods: A descriptive cross-sectional study was conducted on 284 female students in Seto-Semera high school Jimma town, south-western, Ethiopia from April 08-11/2014. Study populations were selected from different educational levels (9th\&10th) using stratified random sampling technique .Data were edited, tallied and analyzed manually by using scientific calculator and presented in texts, tables ,charts and graphs. Results: In this study, 284 female students were participated. Out of this majority of them $238(83.8 \%)$ were between the age of 14-17 years. One hundred thirty of them were Oromo Ethnic group. And two hundred seventy two of those unmarried. Only $115(40.5 \%)$ had heard about EC, 31(27.0\%) of the respondents mentioned the correct recommended timing for oral pills of emergency contraception use. With regarding to attitudes $83(73.0 \%)$ of the respondents had positive attitude from the total heard of emergency contraception methods. Conclusion and Recommendations: knowledge of Emergency contraceptives is low, The major source of information were mass media TV/radio. The majority of students those heard of Emergency contraceptives were not know the correct time limit to Emergency Pills and Intrauterine Contraceptive Device .The absence of correct information about EC could be barrier from being utilization by individual who need Emergency contraceptives (ECs). The utilization of EC was very low this leads to higher chance of unintended. The study recommends that academic institution and should be work on the promotion and enhancement of health education about EC among students of high school.
\end{abstract}

Keywords: Emergency Contraceptive, Knowledge, Attitude, Practice

\section{Background}

Emergency contraceptive is a method of contraception used after intercourse and before the potential time of implantation, offers women a last chance to prevent pregnancy after unprotected intercourse $(1,2)$. Since it is difficult to determine the infertile time of the cycle with certainty emergency contraceptive better be provided for any women who is concerned about her risk of pregnancy, regardless of the cycle day of exposure (3). There are two types of emergency contraceptive. Hormonal methods (pills) and Intrauterine device (IUD).Hormonal emergency 
contraceptives pills consist of a) combined oral contraceptive pills: taken within 72 hours of unprotected sexual intercourse and then 12 hours late. b) Progesterone only pills one pill should be taken as the first dose as soon as convenient, but not later than 3 days (72 hours). After unprotected intercourse to be followed by another one pills 12 hours latter.(4).The general indications for EC are when no contraceptive has been used; when there has been contraceptive accident or misuse and when the women are a victim of sexual assault(4,5).Despite the availability of highly effective methods of contraception many pregnancy are unwanted and unplanned .These pregnancies carry high risk of morbidity and mortality often due to unsafe abortion .Many of these unplanned pregnancies can be avoided using emergency contraception (6). The study result South Africa to assess the knowledge use and attitude of EC among female public sector primary health care 1068 clients only $22.8 \%$ of the clients had heard of emergency contraception. Awareness was lower among older lees educated women and knowledge of EC was superficial, $47.1 \%$ of those who have heard about Emergency contraceptives (EC) were un sure of the appropriate interval between un protected intercourse and starting EC 56.6\% not knowing where it is available .few (9.1\%) of those who knew of EC had used it. After explaining EC attitude towards its use were found to be positive with $90.3 \%$ indicating that they will use it if need arises (7). For over a decade, advocates have sought to improve access to emergency contraception's (EC) across the world. These efforts have been highly successful in Europe and North America, where EC is now widely available over the counter, have generated much debate in Latin America, and are beginning to take hold in Asia $(8,9)$. The rate of unplanned pregnancies varies around the world. The number particularly high among teenagers and poor sectors of the population, but it is also seen among women over 35.both single and married. While the total number of unplanned pregnancies has diminished over the past few decades, the percentage remains high among teenagers (10) who could be due to gap in awareness, negative attitude towards contraception, low accessibility or as a result of sexual assault. At times, the knowledge and practice but no contraceptive is $100 \%$ effective and it is always vary vital to have EC has a backup method $(15,16)$.the annual number of induced abortions, in Africa rose between 2003 and 2008, from 5.6 million to 6.4 million. In 2008, the most abortions cured in Eastern Africa (2.5million), followed by Western Africa (1.8million), Northern and middle Africa (0.9million), and Southern Africa (0.2million)(13).In Africa, however the success of EC programs remained limited. Even in countries where the regulatory environment is favorable, resource constraints within the public sector limit the ability to provide consistent and quality EC services at low cost in growing number of African countries, the private sector has emerged to fill these gapes, increasing access primarily among young affluent urbanites. Low knowledge levels among the general population ultimately undermine the impact of such provision strategies, with as few as $10 \%$ of woman in Senegal and Zambia reporting having ever heard of EC, in the majority of African countries, less than one percent of all women have reported ever using it $(14,15)$.A study finding also indicated that pills and injection were most commonly known and used methods, mentioned by $66.2 \%$ and 64.45 of study subjects respectively(16) Unintended pregnancy can carry serious consequences for women, their families and countries. To list some of them are denying a fundamental human right to control one's own fertility, Limits economic growth, and Negative environmental impact high maternal mortality and morbidity, high infant mortality; impact on child health and development $(17,18)$. In Ethiopia In 2008, 101, unintended pregnancies occurred per 1,000 women aged 15-44.and $42 \%$ of all pregnancies were unintended pregnancy occurred. Per 1000 women age $15-44$ and $42 \%$ all pregnancies were unintended (19-25). This indicates the need for assessing the knowledge, attitude and practice about EC of female students in seto-Semero high school. The study was help for the best future planning and finding to meet adolescents need by removing obstacles, to which they give solutions like by reinforcing \&making right informed decisions on emergency contraception services. If it is used correctly it can help adolescents to prevent unintended pregnancy and its consequences. Therefore the result of this study was help for in solving problems. Of adolescent population by giving emphasize in providing information about emergency contraception recommending ideas on how contraception services would be available to students in and identifying the reason on nonuse of ECs. Thus this study was come up with information related to Knowledge, Attitude and practice of SetoSemero high school female students.

\section{Methods and Materials}

\subsection{Study Area and Period}

The study was conducted in Seto-Semero high school in Jimma town, which located at, $357 \mathrm{~km}$ away from central city of Addis Ababa and $3 \mathrm{~km}$ from Jimma university main compass. The school serves grade $9^{\text {th }}$ and grade $10^{\text {th }}$ students from Jimma town and its adjacent kebeles. According the statics obtained from the school offices a total of 1381students enrolled during 2013/14 academic year. From this 787 are female students with 361 from grade $9^{\text {th }}$ and 426 from grade $10^{\text {th }}$ respectively. The study was conducted in Jimma University campus from April, 08-11/2014 in the university.

\subsection{Study Design}

A descriptive cross sectional study design was conducted to assess knowledge, attitude and practice of emergency contraceptive methods among female students in SetoSemero high school Jimma town, south west Ethiopia.

\subsection{Study Population}

All female students attending their education from Seto- 
Semero high school in academic year of 2013/14.The study populations were included the sampled female students from Seto-Semero high school in academic year.

\subsection{Sample Size}

Since the data was not available on emergency contraception among high school female students in the area, $50 \%$ of population proportion considered to determine sample size based on single population proportion and the level of precision $(d)$ is $(0.05)$.

$$
\mathrm{n}=\left(\mathrm{Z}_{\alpha / 2}\right)^{2} \mathrm{p}(1-\mathrm{P})
$$

$$
\mathrm{d}^{2}
$$

Where

$\mathrm{n}=$ minimum sample size of the study subject

$\mathrm{z}=$ standard normal distribution curve /value for the $95 \%$ confidence interval (1.96)

$\mathrm{p}=$ proportion of population with KAP emergency contraception among high school female students (50\%)

$\mathrm{d}=$ the margin of error taken $(0.05)$

$$
\begin{gathered}
n=\frac{\left(Z_{\alpha / 2}\right)^{2} p(1-p)}{d^{2}} \\
n=\frac{(1.96)^{2}(0.5)(1-0.5)}{(0.05)^{2}}=384
\end{gathered}
$$

since source population $<10,000$ population correction formulas were employed with following formula:

$$
\mathrm{Nf}=\mathrm{n} /(1+\mathrm{n} / \mathrm{N})=384 /(1+384 / 787)=258
$$

$\mathrm{n}=$ minimum sample size (384), $\mathrm{N}=$ total number of female students (787), $\mathrm{Nf}=$ minimum final sample size Thus $\mathrm{nf}=258$. After which $\mathrm{n}_{f}$ become 258 and considering $10 \%$ non-response rate of 26 lastly the final sample size become 284.

\subsection{Sampling Techniques and Procedure}

The required numbers of samples were allocated proportionally among each grade students using stratified sampling technique. A sampling frame of female students from each grade was made and simple random sampling was employed to draw study subjects from each class.

\subsection{Instruments and Measurements}

Pretested and structured questionnaire was used. Data collection tools were adapted after review of relevant literatures. The questions and statement are grouped and arranged according to the particular objectives that they can address.

\subsection{Data Collection Procedure}

Data were collected through self-administered structured questionnaire. Randomly selected students from each class rooms were taken to one class room or hall based on their willingness to participant in the study. They were provided the questionnaire and oriented how to fill the questionnaire.
After filling the questionnaire they were return to the data collectors.

\subsection{Study Variable}

\subsubsection{Dependent Variable}

Knowledge about contraception, Attitude about contraception, Practice about contraception

\subsubsection{Independent Variable}

- Age, Sex, Socioeconomic status, religion place of living, Ethnicity and Marital status

\subsection{Data Processing, Analysis and Presentation}

After data collection each questionnaire was checked for completeness and consistency. Then the data was analyzed manually by using scientific calculator. For descriptive statistics the result was presented in terms of proportions or percentage and association between variables was calculated using chi-square test and p-value $<0.05$ was considered as significant.

\subsection{Operational Definition}

Knowledge : A study subjects awareness on existence of Emergency Contraceptive, type of EC knew time limit to be taken EC after unprotected sex with 72/120 hrs \& occasions when EC was used/not used.

Knowledgeable: scoring of $75 \%-100 \%$ from the knowledge measuring question, if the participants answered $\geq 6$ knowledge measuring question.

Fairly knowledgeable: scoring of $50 \%-74 \%$ from the knowledge measuring questions/answered. 4-5 knowledge measuring question.

Non knowledgeable: scoring of $<50$ from the knowledge measuring questions/answered $<4$ knowledge measuring question (29)

Attitude: Attitude is the study subjects opinion outlook, position and ideas towards EC methods. Study subject who have concerns and negative opinions about EC.

Positive attitude: scoring of $75-100 \%$ from attitude questions.

Negative attitude: Scoring $\leq 75 \%$ attitude measuring questions

Practice: Ever use of EC on the basis of their knowledge when the study subjects are exposed to unprotected sexual intercourse to prevent unintended pregnancy.

\subsection{Data Quality Control}

Data collection instrument was pretested on 5\% similar students from grade $9^{\text {th }}$ and grade $10^{\text {th }}$ of Jiren secondary school to check the validity and reliability. Based the finding possible amendments were made. In addition, data collectors were adequately trained for one day on the administration and checking of completeness of the questionnaire. Supervision by the principal investigator throughout the data collection period was carryout. 


\subsection{Ethical Consideration}

The ethical approval letter of permission was obtained from Jimma university CBE coordination office and official permission was sought from the Seto-Semero high school administrative body to get permission and cooperation. The respondents were informed about the objective and purpose of the study and verbal consent was obtained from each respondents. Also they were informed about their right of not participating in the study. In addition, confidentiality of in formations was assured and privacy of the study populations were respected and kept as well. Moreover, to ensure confidentiality the name of respondents was not being written the consent form. The final report of the study was submitted to Jimma University departments of Nursing and to SetoSemero high school, and CBE office. Finally possible efforts will be made to publish the result on national and international peer reviewed journals.

\section{Results}

\subsection{Socio Demographic Characteristics}

A total respondent 284 were participated in the study which gives $100 \%$ response rate. majority $238(83.8 \%$ ) of the respondents were between 14 and 17 years old age and $46(16.2 \%)$ were between age of 18 and 21 years. regarding religious 108(38.2\%) were Orthodox followed by Islam which accounts $80(28.17 \%), \quad(21.13 \%)$. Majority of $137(48.3 \%)$ of respondents were Oromo, and 76(26.8\%) Amhara, Ethnic group. Two hundred seventy two (95.8\%) of the respondents were unmarried, $8(2.8 \%)$ were married and $4(1.4 \%)$ were divorced respectively. Most of $170(59.84 \%)$ of the respondents were from urban and live with their parents and $114(40.14 \%)$ were from rural and live alone or with peer. Concerning occupational of parents the study subjects,
$125(44.01 \%)$ of them were trader followed by $90(31.7 \%)$ were peasants and $69(24.3 \%)$ one or both parents were governmental worker. (See table 1 below).

Table 1. Distribution of respondents by their socio demographic data at Seto-Semero high school, South West Ethiopia.

\begin{tabular}{llll}
\hline Characteristics & response & number & percent \\
\hline \multirow{4}{*}{ Age } & $14-17$ & 238 & 83.8 \\
& $18-21$ & 46 & 16.2 \\
& total & 284 & 10 \\
& Oromo & 137 & 48.3 \\
Ethnicity & Amhara & 76 & 26.8 \\
& Tigray & 30 & 10.6 \\
& Guragie & 24 & 8.3 \\
& dawro & 23 & 8 \\
Religious & Yem & 14 & 5 \\
& Orthodox & 108 & 38.0 \\
& Islam & 80 & 28.2 \\
& Protestants & 60 & 21.1 \\
& Catholics & 28 & 9.9 \\
& Adventists & 8 & 2.8 \\
Residence & Single & 272 & 95.8 \\
& Married & 8 & 2.8 \\
& Divorced & 4 & 1.4 \\
Grade & Total & 284 & 100 \\
& Total & 130 & 45.8 \\
& 10 & 154 & 54.2 \\
& Urban & 170 & 59.9 \\
& Tural & 114 & 40.1 \\
& & 284 & 100 \\
\hline \multirow{5}{*}{ th } & &
\end{tabular}

\subsection{Knowledge about Emergency Contraception}

One hundred fifteen (40.5\%) of the total respondents had ever heard about emergency contraception methods. From this $(77.6 \%)$ mentioned oral pills, and $(23.4 \%)$ mentioned IUCD. (See fig 1 below)

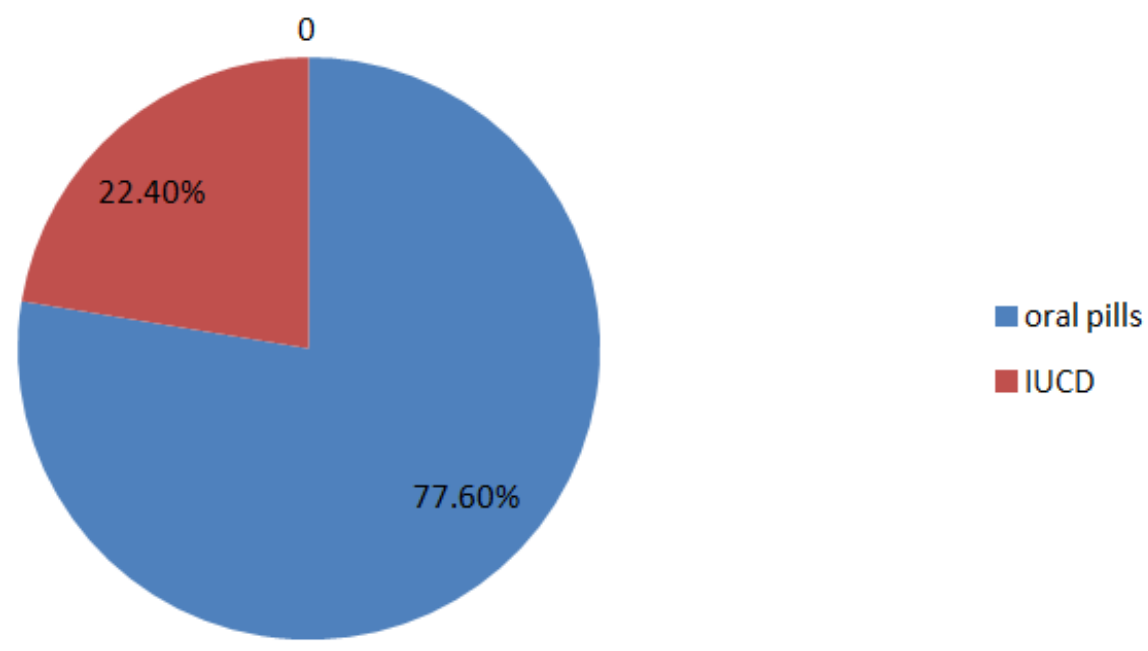

Fig. 1. Knowledge of respondents on methods of Emergency Contraceptive at Seto- Semero high school, south west Ethiopia, 2014.

The major source of information were $41(35.7 \%)$ from mass media, 29(25.2\%) health workers, 20(17.4\%) School and $25(25.2 \%)$ teachers respectively (Fig2). 


\section{Source of informations}

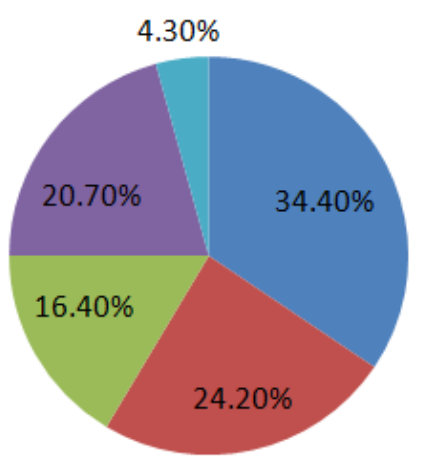

\begin{tabular}{|c|}
\hline \multirow[t]{2}{*}{ Mass media } \\
\hline \\
\hline I school \\
\hline teachers \\
\hline \\
\hline
\end{tabular}

**= indicates friends, Newspaper.

Fig. 2. Source of information of EC of these respondents among female students at Seto-Semero high school, south west Ethiopia, 2014.

Regarding situations of EC taken, majority of those aware of EC 108(93.9 \%) mentioned that EC indicated after unprotected sexual intercourse, 4(3.5\%) when unwanted pregnancy occurred, $3(2.6 \%)$ as ongoing contraception. Most of $70(60.9 \%)$ from health institution, $28(24.3 \%)$ pharmacy, could get this method. And the recommended time between the dose $49(42.6 \%)$ identified as 72 hours apart, $31(27.0 \%)$ mentioned 120 hours apart and $35(30.4 \%)$ were side I do not know.

Table 2. Knowledge assessment of female students at Seto-Semero high school, South West Ethiopia, 2014.

\begin{tabular}{|c|c|c|c|}
\hline Variable & Response & Frequency & Percent \\
\hline \multirow{3}{*}{ Ever heard EC } & Yes & 115 & 40.5 \\
\hline & No & 169 & 59.5 \\
\hline & Total & 284 & 100 \\
\hline \multirow{2}{*}{ Type of EC } & pills & 89 & 77.4 \\
\hline & IUCD & 26 & 22.6 \\
\hline \multirow{4}{*}{ Place of EC obtain } & Health institutions & 70 & 60.9 \\
\hline & Shop & 11 & 9.6 \\
\hline & Pharmacy & 24 & 20.9 \\
\hline & Private clinic & 6 & 5.2 \\
\hline \multirow{3}{*}{$\begin{array}{l}\text { Situation the EC } \\
\text { should be taken }\end{array}$} & $\begin{array}{l}\text { After un protected } \\
\text { sexual intercourse }\end{array}$ & 108 & 93.9 \\
\hline & $\begin{array}{l}\text { When unintended } \\
\text { pregnancy occurred }\end{array}$ & 4 & 3.5 \\
\hline & $\begin{array}{l}\text { Ongoing } \\
\text { contraception }\end{array}$ & 3 & 2.6 \\
\hline \multirow{3}{*}{$\begin{array}{l}\text { Recommended time } \\
\text { for pills effective }\end{array}$} & Within 72 hours & 49 & 42.6 \\
\hline & Within 120 hours & 31 & 27.0 \\
\hline & Do not know & 35 & 30.4 \\
\hline \multirow{3}{*}{$\begin{array}{l}\text { Recommended time } \\
\text { for IUCD effective }\end{array}$} & Within 72 hours & 16 & 13.9 \\
\hline & Within 120 hours & 9 & 7.8 \\
\hline & Do not know & 90 & 78.3 \\
\hline \multirow{2}{*}{$\begin{array}{l}\text { Know how to } \\
\text { prevent un intended } \\
\text { pregnancy }\end{array}$} & Yes & 115 & 40.5 \\
\hline & No & 169 & 59.5 \\
\hline
\end{tabular}

$* *=$ indicates friends,

Concerning the overall level of knowledge about EC, 41(14.4\%) had good knowledge and the rest $182(64.1 \%)$ had poor knowledge (see table 6 below).
Table 3. Assessment of level of knowledge about emergency contraceptives among regular female students of SetoSemero high school, Jimma Zone, South western Ethiopia, 2014.

\begin{tabular}{llll}
\hline S. No & Level of Knowledge & Number & Percent \\
\hline 1 & Good knowledge & 41 & 14.4 \\
2 & Fair knowledge & 61 & 21.5 \\
3 & Poor knowledge & 182 & 64.1 \\
4 & Total & 284 & 100 \\
\hline
\end{tabular}

\subsection{Attitude Towards Emergency Contraception}

One hundred fifteen $(40.5 \%)$ of students who know Emergency Contraceptives (EC were responded to series of questions regarding attitude towards Emergency Contraceptives. From those $(40.5 \%)$ respondents who knew about ECs, 84 (73.1\%) agree to use EC after unprotected sexual intercourse, $74(64.3 \%)$ of them replied that they might give advice to their close friends to use ECs when they faced unintended sexual inter course, and $79(68.7 \%)$ of respondents agree with the likely promotion of prevalence of HIV and other STDs when use of ECs in the society increased, on the other hand 54(47.0\%) agree unplanned sexual intercourse was problem of all young females. Majority of 91(79.1\%) were replied disagree for ECs affects ongoing regular methods of contraception. (See table 4 below).

Table 4. Attitudes of Emergency Contraceptive among female students in Seto-Semero high school female students, Jimma Zone, South western Ethiopia, 2014.

\begin{tabular}{|c|c|c|c|}
\hline Variables & Characteristics & Numbers & Percent \\
\hline \multirow{4}{*}{$\begin{array}{l}\text { If I had unintended } \\
\text { sexual inter course I } \\
\text { would use EC }\end{array}$} & Agree & 84 & 73.1 \\
\hline & Disagree & 12 & 10.4 \\
\hline & Neutral & 19 & 16.5 \\
\hline & Total & 115 & 100 \\
\hline If a closed friends have & Agree & 74 & 64.3 \\
\hline unintended sexual & Disagree & 24 & 20.9 \\
\hline intercourse I would & Neutral & 17 & 14.8 \\
\hline advise her to use EC & Total & 115 & 100 \\
\hline Wide spread of ECs & Agree & 79 & 68.7 \\
\hline will increase the risk of & Disagree & 17 & 14.8 \\
\hline STI included & Neutral & 19 & 16.5 \\
\hline HIV/AIDS & Total & 115 & 100 \\
\hline
\end{tabular}




\begin{tabular}{|c|c|c|c|}
\hline Variables & Characteristics & Numbers & Percent \\
\hline \multirow{5}{*}{$\begin{array}{l}\text { ECs promote } \\
\text { promiscuity }\end{array}$} & Agree & 87 & 75.7 \\
\hline & disagree & 18 & 15.6 \\
\hline & Neutral & 10 & 8.7 \\
\hline & Total & 115 & 100 \\
\hline & Agree & 14 & 12.2 \\
\hline \multirow{3}{*}{$\begin{array}{l}\text { ECs is one way of } \\
\text { abortions }\end{array}$} & Disagree & 84 & 73.0 \\
\hline & Neutral & 17 & 14.8 \\
\hline & Total & 115 & 100 \\
\hline \multirow{4}{*}{$\begin{array}{l}\text { I don't want to use ECs } \\
\text { for fear of side effects }\end{array}$} & Agree & 49 & 42.6 \\
\hline & Disagree & 52 & 45.2 \\
\hline & Neutral & 14 & 12.2 \\
\hline & Total & 115 & 100 \\
\hline \multirow{4}{*}{$\begin{array}{l}\text { ECs will affect ongoing } \\
\text { regular contraception's } \\
\text { negatively y }\end{array}$} & Agree & 4 & 3.5 \\
\hline & Disagree & 91 & 79.1 \\
\hline & Neutral & 20 & 17.4 \\
\hline & Total & 115 & 100 \\
\hline \multirow{4}{*}{$\begin{array}{l}\text { It is a good idea to avail } \\
\text { ECs for all female } \\
\text { students }\end{array}$} & Agree & 47 & 40.9 \\
\hline & Disagree & 39 & 33.9 \\
\hline & Neutral & 29 & 25.2 \\
\hline & Total & 115 & 100 \\
\hline \multirow{4}{*}{$\begin{array}{l}\text { Un planed sexual } \\
\text { intercourse is problem } \\
\text { of all young females }\end{array}$} & Agree & 54 & 47.0 \\
\hline & Disagree & 41 & 35.6 \\
\hline & Neutral & 20 & 17.4 \\
\hline & Total & 115 & 100 \\
\hline \multirow{4}{*}{$\begin{array}{l}\text { ECs can used } \\
\text { continuously for long } \\
\text { time }\end{array}$} & Agree & 8 & 7.0 \\
\hline & Disagree & 74 & 64.3 \\
\hline & Neutral & 33 & 28.7 \\
\hline & Total & 115 & 100 \\
\hline
\end{tabular}

positive attitude and the rest $51(44.4 \%)$ had negative attitude. (See table 5 below).

Table 5. Assessment of level of attitude towards Emergency Contraceptive Pills among regular female students of teachers training college, Jimma Zone, South Western Ethiopia, 2014.

\begin{tabular}{lll}
\hline Level of attitude & No & \% \\
\hline Positive attitude & 64 & 55.6 \\
Negative attitude & 51 & 44.4 \\
Total & 115 & 100 \\
\hline
\end{tabular}

\subsection{Practice of Emergency Contraceptive (EC) of the Respondents}

Out of the study participants 126 were experienced sexual intercourse out of them $16(5.63 \%)$ had unprotected sex. and $4(25.0 \%)$ were used EC. From those $3(75 \%)$ used oral pills, $1(25 \%)$ use Intra Uterine Contraceptive Pills(IUCD) after unprotected sexual intercourse within 72 hours and 120 hours. And the rest not use EC. Regarding reasons not use EC $6(2.11 \%)$ do not know from where to get $4(25.0 \%)$ do not know its availability $2(12.5 \%)$ were unwillingness of health workers.

Concerning the overall attitude level 64(55.6\%) had

\section{Ever use of ECs}

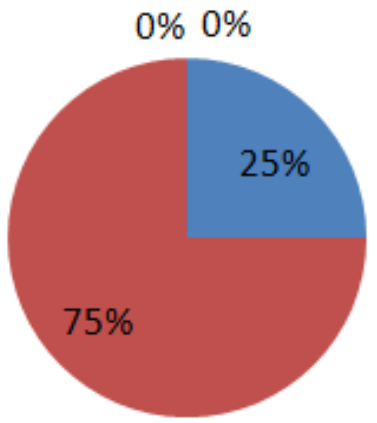

Yes

No

Fig. 3. Practice of Emergency Contraceptive method by female students at Seto Semero high school female students Jimma Zone, South Western Ethiopia,2014.

Table 6. Distribution of respondents by their practice of Emergency Contraceptives at Seto Semero High school female students Jimma Zone, South Western Ethiopia, 2014

\begin{tabular}{llll}
\hline Characteristics & Category & NO & \% \\
\hline \multirow{3}{*}{ Ever had sex } & Yes & 126 & 44.4 \\
& No & 158 & 55.6 \\
& Total & 284 & 100 \\
Had unprotected sex & Yes & 16 & 12.7 \\
& No & 110 & 87.3 \\
& Total & 4 & 100 \\
& Health workers unwilling & 3 & 25.0 \\
Why did not use EC & Drugs unavailable & 5 & 18.7 \\
& Do not know from where to get & 2 & 31.3 \\
& Fear of social stigma & 2 & 12.5 \\
& Health institution is far to get & 16 & 12.5 \\
Types used after unprotected sex & Total & 3 & 100 \\
& Oral pills & 1 & $75 . .0$ \\
\end{tabular}




\begin{tabular}{llll}
\hline Characteristics & Category & NO & \% \\
\hline & Within 72 hours & 3 & 37.5 \\
Times have taken the method & Within 120 hours & 2 & 25.0 \\
& Do not know & 3 & 37.5 \\
& Total & 8 & 100 \\
& Female friends & 3 & 25.0 \\
Who told you to use EC & Mail friends & 2 & 25.0 \\
& Health workers & 3 & 25.0 \\
Faced unintended pregnancy & Total & 8 & 100.0 \\
& Yes & 4 & 3.2 \\
& No & 122 & 96.8 \\
\hline
\end{tabular}

\section{Discussion}

This study aimed to assess the knowledge, attitude, and practice on Emergency contraceptives among female students in Seto-Semero high school. In this study $40.5 \%$ of the total respondents had heard about EC, and $77.4 \%$ of those ever heard of EC mentioned pills \& 22.6. \% mentioned IUCDs. This is slightly lower than study conducted on Addis Ababa university and unity university students $43.5 \%$ of the female students have heard of EC and among them $82.8 \%$ mentioned pills and 34.2\% mentioned Intra Uterine Contraceptive Pills(IUCD) (26).This difference might be due to the university students might have more access for information of Emergency Contraceptive(EC). Most source of information mentioned in the study were $(35.6 \%)$ from mass media TV (radio) (25.2\%) health professions (17.4\%) school and $(15.7 \%)$ friends. Mekele University indicates that major source of information were TV, radio which accounts $34.3 \%$. and family (friends) (26)the possible reasons may be due to mass media more access in the campuses and students living out of campuses as in this study have less exposure to media information .One hundred fifteen $(40.5 \%)$ of those ever heard EC, knew the time limit of ECP, $(42.6 \%)$ were identified recommended time limit. The study done on Mekele University $88 \%$ of those ever heard of EC mentioned pills and $58.8 \%$ of them identified (27).This difference might be due to university students had more awareness than high school students. Out of the study participants only $(7.8 \%)$ had identified recommended time for IUCD within 5 day, similar study done conducted on Addis Ababa University and Unity University (34.2\%) of those who have heard of EC mentioned IUCD only $(8.7 \%)$ could tell the correct time of administration of IUCD the possible reason may be location awareness on EC (26).Concerning their attitude (36.5\%) had positive attitude toward EC should be available for all females. This is slightly lower than the study conducted on under graduate female Mekele students $76 \%$ of those ever heard (44.3\%) of EC had positive attitude toward EC should be available to all women (28). This difference might be due to time gab of study. This study related that $126(44.4 \%)$ of respondents were experienced sexual intercourse from those sexual experienced $4(3.2 \%)$ were faced unwanted pregnancy. The study conducted on Addis Ababa university and unity university students $(59.5 \%)$ of the total respondents have ever had sex in the past (35.1\%) of them had pregnant so the report that their pregnancy were unwanted when compared to the study $44.4 \%$ of respondents had sex which is less than Addis Ababa university and unity university the difference may be due to Seto Semero high school female students live with their parents which might had affect on sexual activities of Seto Semero high school female students. Out of this experienced sexual intercourse only (6.3\%) were used EC. According to study conducted in Addis Ababa university students (49\%) had every used their method when compared to the study its high. The difference is due to the university students are more awareness on access, availability and confidence of students than high school students (26).

\section{Strength and Weakness}

\subsection{Strength of the Study}

The data was collected using a structured self-administered pre-tested questionnaire

Adequate sample size was applied according to single population proportion formula

Data collators were health professional

\subsection{Weakness of the Study}

During this study there may be observational bias

There was financial constraint while conducting the Study

All respondents were interviewed but some of them observed during the study period

Some of the respondents were volunteer during data collection

\section{Conclusion}

The study finding showed that the knowledge of emergency contraception from the total respondent is low. Most of the respondents who have ever heard of emergency contraception had positive attitude. The majority of students from those heard of EC were not knew the correct time limit to ECP and IUCD. The utilization of EC was very low this leads to higher chance of unintended pregnancy. Therefore, the academic institution should work on the promotion and enhancement of health education and counseling about EC, for Seto Semero high school. Female students, Established reproductive health clubs in the school to address targeted issue including ECs, Integration of reproductive health issue to the curriculum. In addition, the use of emergency contraception among 
participants of this study is far less. Hence, there should be an intervention designed to expand service availability particularly at high school female students.

\section{Author's Contributions}

AT, have made substantial contributions to beginning and design, collection of data, analysis and interpretation of data and in drafting the manuscripts and correcting the comment given by the advisors.

ADB involved in revising the research paper and the manuscript critically for important intellectual context and approval of the final version to be published and participated in its design and coordination. He participated in the approval and funding process, participated in the design of the study participated in its design and coordination.

TT, involved in revising the research paper and the manuscript critically for important intellectual context and approval of the final version to be published and participated in its design and coordination.

AAG, had greater contribution in reviewing the manuscript English and topography. And helped to draft the manuscript.

YYA had greater contribution in reviewing the manuscript English and topography. And helped to draft the manuscript.

BAA, had greater contribution in reviewing the manuscript English and topography. And helped to draft the manuscript.

\section{Acknowledgements}

We are thankful to all our department technical staffs for their excellent technical support. We are grateful to all the participants for their cooperation and Jimma University for financial support for only completed this research. In addaition, we would like to acknowledge for Journal whose helped us for free publication.

\section{References}

[1] United States Agency International Development (USAID)/DELIVER (2011). Contraceptive Security Indicators, http://deliver.jsi.com/dhome/whatwedo/commsecurity/csmeas uring/csindicators)

[2] Dray. S (2012). Unplanned pregnancy statistics. http://www.ehow.com/about 4611925 unplanned pregnancystatistics. html. accessed on March 10, 2012

[3] Mosher W. D. Jones J. (2012).Use of contraception in the United States: 1982-2008. National centre for health statistics. Vital health stat.23 (29). available at: http://www.cdc.gov/NCHS/datd/series/sr23/sr2329.pdf.accessed 27 march 2012.

[4] Palermo, T., Bleck, J., Westley ,E. (2014). Knowledge and use of Emergency contraception: A Multicounty Analysis. International Perspectives on sexual and reproductive Health. 40(2):79-94.

[5] ESOG (2012). Emergency contraception, Guideline 2002, available at: http://www.esog.org. et. Accessed. On Oct 28, 2012.
[6] Westley, E., Kapp, N., Palermo, T., Bleck, J. (2013). A review of global access to emergency contraception. International Journal of Gynecology and Obstetrics. Http://dx.doi.org/10.1016/j.ijgo.2013.04.019.

[7] James, T.J, Raymond, E (2012) .Emergency contraception: A. Last chance to prevent unintended pregnancy: http://ec.Princeton. Edu Accessed on March 10.2012'

[8] Myer, L., Mlobeli, R., Cooper, D., Smit, J., Morroni, C. (2007). Knowledge and use of emergency contraception among women in the Western Cape province of South Africa: a cross-sectional study. BMC Women's Health. 7:14:1-7. http://www.biomedcentral.com/1472-6874/7/14

[9] Warren, F. (2014).The council expanded access to emergency contraceptive (EC) in public-and private -sector facilities by training providers and creating awareness about its availability and correct use: Mainstreaming emergency contraception in Kenya. Population council. http://www.popcouncil.org/research/mainstreamingemergency-contraception-in-kenya

[10] Singh, S., Sedgh., G. Hussain., R. (2010). Unintended pregnancy: worldwide levels trends. And out comes, Stud Famplann. 41(4): 241-250.

[11] Central Statistical Authority (CSA) and United Nations Population Fund (UNFPA), Ethiopia, Summary and Statistical Report of the 2007 Population and Housing Census, Population Census Commission (Addis Ababa, Ethiopia: UNFPA, 2008

[12] Mainstreaming Emergency contraception in Kenya. Final project Report 2009. http://www.psi.org/wp content/uploads/2014/10/Mainstreaming_Emergency_Contrac eption_Pills_in_Kenya.pdf

[13] Facts on abortion in Africa. http://www.guttmacher.org/pubs/IB AWW- Africa.pdf. Accessed on March 10, 2012

[14] Facts on un intended pregnancy and abortion in Ethiopiahttp://www.ipas.org/publications/asset upload file440 5002.pdf.accessed on March 10.2012)

[15] Gebremicheal, H., Haile, F., Dessie, A., Birhane, A., Alemeyehu, M., Yebyo, H(2014). Acceptance of long acting contraceptive methods and associated factors.Science Jouranl of Public health 294): 349-355. Http://www.sciencepublishinggroup.com/j/sjph.

[16] Malalu,PK.,Alfred,K.,Too,R.,Chirchir,A.(2014). Determinants of use of modern family planning methods: A case of Baringo North District, Kenya. Science Journal of Public Health.295):424-

430.doi.10.11648/j.sjph.20140205.18.http://www.sciencepubli shinggroup.com $/ \mathrm{j} / \mathrm{sjph}$.

[17] Mir, A S., Malik ,R. (2010). Emergency contraceptive pills: Exploring the knowledge and attitudes of community health workers in a developing Muslim country. N Am J Med Sci. 2(8): 359-364. doi: 10.4297/najms.2010.2359

[18] Tajure N., Pharm B. (2010). Knowledge, attitude and practice of emergency contraception among graduating female students of Jimma University, Southwest Ethiopia. Ethiop J Health Sci. 20(2): 91-97. PMid:22434966, PMCid:PMC3275837 
[19] Singh S, Darroch J. E., Ashford LS(2014). Adding It Up: The Costs and Benefits of Investing in Sexual and Reproductive Health 2014, New York: Guttmacher Institute, 2014. http://www.guttmacher.org/media/experts/Darroch.html

[20] Magnus Hirschfield Archive for sexology worldwide statistic: http://www2huberlin.de/ECE2/html/world-wide statistics .html/accessed on March10, 2012.

[21] Longwe, A., Huisman ,J.,Smits, J. (2012). Effects of knowledge, acceptance and use of contraceptives on household wealth in 26 African Countries. NICE Working Paper 12-109.Http://www.ru.nl/nice/workingpapaers.

[22] Milikalew, D. et al (2009).Towards sexual transmitted disease in Boditi high school students, southern Ethiopia, May 2009.

[23] Ipas (2012). Children, youth and unsafe abortion, 2007 available at at: http//www.iwhe/resources accessed on Oct, 2012.

[24] James Trussell J, Raymond, E (2012): Emergency contraception: A. Last chance to prevent unintended pregnancy: http://ec.Princeton.edu Accessed on March10.2012'

[25] Wegene Tamire,W.,, Fikre Enqueselassie, F.(2007). Knowledge, attitude, and practice on emergency contraceptives among female university students in Addis Ababa, Ethiopia. Ethiop.J.Health Dev. 21;(2):111-116

[26] Ambo F., Mossies' A., Gobena T. (2010).Sexual practices and their development pattern among Jimma university students: Thiop J health sci. 20(3):1-5.

[27] Pharm,B.. Tajure, N.(2010). Knoweldge, attitude, and practice of emergency Contraception among graduating female students of Jimma University, South West Ethiopia. Ethiop J Health Sci.20(2):91-97.

[28] Wegeene. T., Fikrie E. (2007). Assessments of Knowledge, Attitude, and Practice on Emergency Contraceptives among female University students in Addis Ababa, Ethiopia, Ethiopia. J health Dev 21(2)

[29] Abera,H., Mokonnen,M., Jara,D.(2014). Knowledge, Attitude, Utilization of Emergency Contraceptive and Associated Factors among Female Students of Debre Markos Higher Institutions, Northwest Ethiopia, 2014.Fam Med Sci Res 2014, 3:4 http://dx.doi.org/10.4172/2327-4972.1000149

[30] Gebreyohannes, E. (2009). Assessments of Knowledge, Attitude and practice on Emergency Contraceptives among University female undergraduate in Tigray Regional State. Mekele town, 2009 Bsc thesis-public. 